\title{
Calculation of the optimal number of nurses based on nursing intensity by patient classification groups in general units in South Korea: A cross-sectional study

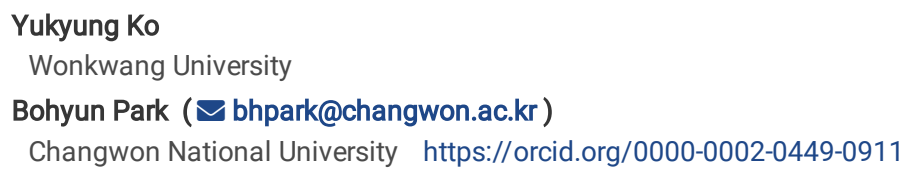

Research article

Keywords: Nursing intensity, Nursing time, Patient classification, General units

Posted Date: February 28th, 2022

DOI: https://doi.org/10.21203/rs.3.rs-585921/v2

License: (c) (i) This work is licensed under a Creative Commons Attribution 4.0 International License. Read Full License 


\section{Abstract}

Background: Calculating the accurate number of nursing personnel based on a patient classification system that clearly reflects the nursing needs of patients is a problem directly related to the nursing unit's budget management, productivity, etc. This study aimed to calculate the total daily nursing workload and the optimal number of nurses per general unit based on the nursing intensity and direct nursing time per inpatient through patient classification.

Methods: Three units at one general hospital were investigated. To calculate nursing intensity, patient classification according to nursing needs was performed for over 10 days in each unit in September 2018. The direct and non-direct nursing time and nursing intensity scores were analyzed using descriptive statistics (e.g. frequency, percentage, and average) generated using Microsoft Excel.

Results: For the internal medicine unit, the average direct nursing time per patient was 1.0, 1.5, 2.2, and 2.9 hours for Groups 1, 2,3 and 4, respectively. For the surgical unit, the average direct nursing time per patient was $0.9,1.4,2.1$, and 2.6 hours for Groups $1,2,3$, and 4 , respectively. For the comprehensive nursing care unit, the average direct nursing time per patient was $0.8,1.2,1.7$, and 2.2 hours for Groups $1,2,3$, and 4 . The optimal number of nurses was 25 in the internal medicine unit, 37 in the surgical unit, and 22 in the comprehensive nursing unit. There was a shortage of five nurses in the internal medicine unit and nine in the surgical unit.

Conclusion: Based on the nursing time according to patient classification groups, this study confirmed that the optimal number of nurses cannot be secured and that the nursing intensity is very high. This study's results suggest that long-term efforts, such as improving the nursing environment, should be made to secure an optimal number of nurses in various hospital nursing units.

\section{Background}

Estimating the accurate number of nursing personnel according to nursing needs using a patient classification system that clearly reflects patients' nursing needs is an issue directly related to the budget management and productivity of the concerned nursing unit. Such suboptimal nurse

staffing in hospitals can affect patient care's quality and nurses' health and well-being [1]. Therefore, if nursing intensity based on nursing needs can be calculated by using a more sophisticated patient classification tool and the calculation criteria for nurse staffing can be more elaborately designed, realistic standards for nursing unit operations can be established.

Currently, the optimal number of nurses per nursing unit can be calculated using a method based on nursing time by patient classification groups [2]. This approach involves quantifying nursing time taken according to patients' nursing needs and is limited in considering the differences in qualitative characteristics, such as available resources for each hospital and unit, nurses' qualifications, and nurses' competencies. Since it cannot realistically reflect nursing time taken according to the severity of inpatients' diseases in clinical settings and does not record time-consuming nursing activities-such as dealing with difficult caregivers-this approach does not reflect the reality of clinical nursing practice [3]. In South Korea, a financial incentive policy regarding nurse staffing-the nursing fee differentiation policy (NFDP) - was implemented in 1999 [4]. The NFDP comprises a seven-grade nurse staffing system, where each grade reflects the nurse-to-beds ratio in general hospitals [5]. These nurse staffing policies aim to improve the environment and create positive practices in healthcare services to ensure the appropriate levels of nurse staffing [6].

Most previous studies measuring nursing time have used direct measurement methods such as the work sampling method and time-and-motion studies [7]. Since nurse staffing is calculated based on the required nursing time per patient, the required nursing time should be measured and predicted using tools [8]. While traditional time studies using a direct measurement method require much time and effort, such a method does not comprehensively reveal the attributes of nursing activities and essence of nursing care. Since nursing activities are complex, with several occurring simultaneously, there are practical limitations to their estimation by breaking them down and measuring them individually [9]. Therefore, there is a need to develop a new method that can more efficiently measure nursing time based on a comprehensive approach.

Santos et al. [10] suggested that working time should be described in three dimensions: the duration, distribution, and intensity. Working time refers to the total time spent on work. The distribution refers to how it is spread across days, weeks, months, and years; it includes intermittent work, compensatory time, home office or remote work, and all the free time used to obtain qualifications to work more competently. To determine nurse staffing levels, managers need to understand the underlying determinants-patient (patients' nursing needs based on their acuity and dependency levels), ward (patient throughput), and nursing staff (number and skill level) factors [11]. One of the challenges faced by managers responsible for staffing is trying to understand the influence of the multiple factors that make up each individual care environment [12].

Meanwhile, Fagerström et al. [9] in Finland defined nursing intensity per patient as the sum of the means of the weighting coefficients per patient classification group divided by the number of nurses, presenting a method for relatively concisely quantifying nursing intensity. Fagerström et al. [9] believed that this method would enable comparisons of nursing intensity between various nursing units and the accumulated data can be used as a basis for resource allocation in hospitals. This study attempted to calculate the optimal number of nurses in general units in South Korea by applying the method developed by Fagerström et al. to inpatients in nursing units using the calculated nursing intensity and the total working time taken for each nurse. The nursing time by patient classification groups was calculated using a comprehensive rather than a direct measurement method, which saves not only time but also the costs required for the calculation and is, thus, highly likely to be used in nursing units. The findings can be used as basic data for calculating the optimal number of nurses required in nursing units, establishing effective nurse staffing strategies, and enabling better management of human resources.

\section{Objectives}


This study aimed to calculate the total daily nursing workload per nursing unit and the optimal number of nurses based on the nursing intensity and direct nursing time per inpatient. The specific objectives were as follows:

1. to calculate direct and non-direct nursing time by investigating the total working time, non-direct nursing time, and personal time perceived by nurses in each nursing unit (internal medicine, surgical, and comprehensive nursing care units);

2. to calculate and compare nursing intensity in nursing units based on patient classification scores;

3. to calculate nursing intensity and direct nursing time taken per patient by patient classification groups in the nursing units; and

4. to calculate the total daily nursing workload and the optimal number of nurses per nursing unit based on the nursing intensity and nursing time by patient classification groups.

\section{Methods \\ Research design}

This study was a descriptive research aimed at not only investigating nursing intensity through patient classification based on nursing needs, but also calculating direct nursing time per inpatient, total daily nursing workload, and the optimal number of nurses in each nursing unit based on the non-direct nursing time (indirect nursing time and break time) perceived by nurses. The STROBE (Strengthening the Reporting of Observational Studies in Epidemiology) checklist for cross-sectional studies was followed to strengthen this study's methodological rigor.

\section{Data collection}

This study involved the following four steps. In the first step, all patients admitted to the nursing units were classified into four groups according to their nursing needs; the mean patient classification score for each group was first calculated, after which the nursing intensity score for each nursing unit was calculated. In the second step, direct and non-direct nursing times, including personal time and break time for all nurses working in the nursing units, were calculated. In the third step, direct nursing time per patient classification group was calculated based on the results of the first and second steps. In the fourth step, the total daily nursing workload and the optimal number of nurses in the nursing units were calculated using direct nursing time by patient classification groups.

In this study, nurses working in wards measured nursing needs using the general ward patient classification tool developed by Ko and Park [13]. The three nursing units (internal medicine, surgical, and comprehensive) of a tertiary general hospital were selected for this study. At the time of the investigation, 20,28 , and 22 nurses belonged to the internal medicine, surgical, and comprehensive wards, respectively. All the data were collected under informed consent.

\section{Participants}

To classify patients according to their nursing needs and calculate nursing intensity, three nursing units at a single tertiary general hospital in $\mathrm{J}$ Province, South Korea, were selected as the study units. The comprehensive nursing care unit is a unit equipped with necessary features, such as appropriate nursing personnel and enhancing the nursing work environment by providing necessary care services to patients without a family caregiver or a privately employed one. The number of patients per nurse in the comprehensive nursing care unit is lower than that in the general units [14]. Given that the comprehensive nursing care unit system in South Korea is expanding and revolutionizing nursing work and the nurse staffing system, it was included in this study.

According to nursing needs, patient classification and nursing time in each unit were investigated over 10 days between September 1 and 30,2018 , excluding weekends. Night shift nurses in charge of the three nursing units performed patient classification of all patients admitted to their units using the Korean Patient Classification System on Nursing Needs for Intensive Care Units (KPCSNI), a tool developed by Ko and Park [13]. The total number of patients who were subjected to classification comprised 473,278 , and 143 patient-days in the internal medicine, surgical, and comprehensive nursing care units, respectively. The three nursing units (internal medicine, surgical, and comprehensive) of a tertiary general hospital were selected for this study. At the time of the investigation, 20, 28, and 22 nurses belonged to the internal medicine, surgical, and comprehensive wards, respectively. (Table 1).

Table 1

The participants during data collection period

\begin{tabular}{|llll|}
\hline \multicolumn{4}{|c}{ The participants during data collection period } \\
& Internal medicine unit & Surgical unit & Comprehensive unit \\
\hline Number of nurses & 20 & 28 & 22 \\
\hline Person-day for 10 days (nurses) & 87 & 125 & 77 \\
\hline Patient-day for 10 days (patient) & 473 & 278 & 143 \\
\hline
\end{tabular}

The nursing time of all nurses in the nursing units who performed patient classification were investigated on that same day in the relevant nursing unit. Nurses who worked day, evening, or night shifts were instructed to complete a self-report questionnaire immediately after the end of their working, thereby minimizing recall errors. The number of nurses who participated in the survey of nursing time comprised 87,125 , and 77 person-days in the internal medicine, surgical, and comprehensive nursing care units, respectively, totaling 289 person-days.

\section{Definitions of terms}

\section{Patient classification}

The patient classification system is a method of classifying patients according to the amount and complexity of nursing care provided to them over a certain period [15]. Here, it refers to classifying patients admitted to the units into groups 1 to 4 using the KPCSNI. As the patient classification group number increases from 1 to 4 , the total score for each item increases, indicating that patients' nursing needs are higher.

Page $3 / 12$ 


\section{Nursing intensity}

Nursing intensity refers to direct and non-direct nursing activities related to patients; it includes patients' dependency, severity of the disease, complexity of nursing care, and time required for nursing as factors directly affecting such nursing activities [16]. To calculate nursing intensity, patient classification scores were calculated using a tool that was modified and supplemented based on the one developed by Ko and Park [13]. This tool comprises 50 direct nursing activities covering eight domains (symptom management infection control, nutrition and medication, personal hygiene and secretion, activity, sleep and rest, guidance in nursing/emotional support, nursing activity planning, and coordination), and 11 indirect activities. Based on the calculated patient classification scores, the weighting coefficient per nursing unit, that is nursing intensity, was calculated following a method used by Fagerström et al. [9].

\section{Personal time}

Personal time excludes direct and non-direct nursing activity times during working time and includes meal and rest times.

4. Non-direct nursing time

Non-direct nursing activities include managing the necessary items and environment for nursing and maintaining the operation of nursing units except for direct nursing care for patients [17]. Non-direct nursing time refers to the sum of the nursing time required for handover, making rounds, work delay, recording, patient-related calls and deliveries, administrative affairs, cognitive workload, education/supervision, research, and so on, as measured using the patient classification tool developed by Ko and Park [13].

\section{Direct nursing time}

Direct nursing time refers to nursing time [17] for providing direct nursing care to patients, as well as preparing and organizing nursing care. Here, it refers to total working time after subtracting personal and indirect nursing times.

\section{Measurement}

1. Patient classification and calculation of nursing intensity for nursing units based on nursing needs Patient classification based on nursing needs was conducted using the KPCSNI. This tool is a factor-type classification tool and includes scores for the clinical features of patients in addition to scores for nursing needs when calculating patient classification scores. It consists of 8 domains and 18 subdomains covering 50 nursing activities. After the tool was reviewed by the researchers, its content validity was tested in consultation with six nursing professors. The average daily value of the calculated patient classification scores for each date was calculated. As a result, a patient classification score of 1-30 points was classified as Group 1, a score of 31-60 points was classified as Group 2, a score of 61-90 points was classified as Group 3, and a score of 91 points or more was classified as Group 4 based on the results of the study by Ko and Park [13].

Nursing intensity was measured following the calculation method presented in a study by Fagerström et al. [9]. After setting the patient classification score in Group 1 as the reference value of " 1 ," the patient classification scores in groups $2-4$ were each divided by the patient classification score in Group 1 to calculate nursing intensity weighting coefficients for the groups. Nursing intensity scores for nursing units were calculated by multiplying the weighting coefficient for each group by the number of patients in each group and then summing up the values. Fagerström et al. [9] propounded the "Professional Assessment of Optimal Nursing Care Intensity Level" (PAONCIL), a new method that goes beyond the traditional time study methodology. It calculates nursing intensity based on patient classification results and assesses nursing intensity for nursing units by reflecting statistical estimations and expert opinions. Fagerström et al. [9] suggested this method as an alternative to the classical time studies, stating that it could establish optimal nursing intensity levels for individual units.

2. Calculating nursing time

Nursing time was measured using a questionnaire developed by this study's researchers with reference to non-direct nursing activities in a tool developed by Ko and Park [13]. This questionnaire comprises 28 items, including total working, break, and non-direct nursing times of the day. Total working time was calculated based on the time at which nurses logged into work and left for the day, while the break time was calculated by summing up the meal and rest times. Non-direct nursing time was calculated by summing the time for each subdomain of the three domains (nursing activity planning and coordination, non-direct activity, and break time). Direct nursing time was calculated by subtracting the non-direct nursing time including leisure time from the total working time (Formula 1). The validity of the direct nursing calculation method was reviewed by six nursing professors and one expert.

$$
\text { Formula1: } \sum_{\mathrm{i}=1}^{\mathrm{n}} \mathrm{DNT}_{\mathrm{i}}=\sum_{\mathrm{i}=1}^{\mathrm{n}} \mathrm{TWT}_{\mathrm{i}}-\sum_{\mathrm{i}=1}^{\mathrm{n}} \mathrm{NDNT}_{\mathrm{i}}
$$

DNT = Direct nursing time

TWT $=$ Total working time

NDNT = Non-direct nursing time

$\mathrm{n}=$ Number of nurses in a nursing unit

3. Calculating direct nursing time per inpatient by patient classification groups

To calculate direct nursing time by patient classification groups, direct nursing time per nursing intensity point was calculated (Formula 2). This value was then multiplied by the weighting coefficient for each patient classification group to calculate direct nursing time per inpatient by patient classification groups (Formula 3). 


$$
\text { Formula } 2: D N T p N I=\frac{\sum_{i=1}^{n} D_{i}}{\sum_{i=1}^{m} N_{i}}
$$

DNT $p$ Nl: Direct nursing time per nursing intensity weighting coefficient

DNT: Direct nursing time

$\mathrm{Nl}$ : Nursing intensity weighting coefficient

$\mathrm{n}$ : Total number of nurses in a nursing unit

$\mathrm{m}$ : Total number of inpatients in a nursing unit

\section{Formula3: DNTpP $=\mathrm{WC}_{\mathrm{i}} \times \mathrm{DNTpNI}$}

DNT $p$ P: Direct nursing time per patient

WC: Weighting coefficients

DNT $p$ Nl: Direct nursing time per nursing intensity weighting coefficients

i: Patient classification group

3. Calculating the optimal number of nurses

The optimal number of nurses in the internal medicine, surgical, and comprehensive nursing care units was estimated by applying the calculated nursing time results to formulas 4-6. After non-direct nursing time was calculated using the ratio (20\%) of non-direct nursing time to the total nursing working timecalculated with the nursing time analysis results-the total nursing time was calculated (Formula 5). The optimal number of nurses was calculated by adding $40 \%$ to the value obtained by dividing the total nursing work time by the mean daily work hours (Formula 6 ).

The total number of annual holidays in the current clinical reality is estimated to be about 134 days, considering weekly holidays: 52 weeks $\times 2$ (Saturday and Sunday) based on an average of 20 working days per month, plus 15 legal holidays (excluding Sundays), 15 basic annual holidays, and additional annual holidays according to the nurses' professional positions. Although 1.4 can be assigned as an additive value due to the number of holidays by rounding off $1.37[(134+365) / 365]$, a constant of 1.6 was used in this study following previous studies $[18,19]$.

$$
\text { Formula4: } \mathrm{TDNT}=\left(\mathrm{m}_{1} \times \mathrm{DNTpPt}_{1}\right)+\left(\mathrm{m}_{2} \times \mathrm{DNTpPt}_{2}\right)+\left(\mathrm{m}_{4} \times \mathrm{DNTpPt}_{3}\right)+\left(\mathrm{m}_{4} \times \mathrm{DNTpPt}_{4}\right)
$$

Formula $5: \mathrm{TNW}=\mathrm{TDNT}+\mathrm{TNDNT}=\mathrm{TDNT}+\mathrm{TDNT} \times \frac{20}{80}$ Formula6 $:$ ONN $=\frac{\mathrm{TNW}}{8} \times 1.6$

TDNT: Total direct nursing time

$\mathrm{DNTpP}_{1}$ : Direct nursing time per patient for Group 1

$\mathrm{DNTpP}_{2}$ : Direct nursing time per patient for Group 2

$\mathrm{DNTpP}_{3}$ : Direct nursing time per patient for Group 3

$\mathrm{DNTpP}_{4}$ : Direct nursing time per patient for Group 4

$m_{1}$ : Number of patients in Group $1 ; m_{2}$ : Number of patients in Group 2; $m_{3}$ : Number of patients in Group 3; $m_{4}$ : Number of patients in Group 4

TNDNT: Total non-direct nursing time

ONN: Optimal number of nurses

TNW: Total nursing workload of the nursing unit

$8=$ Working time per day

$1.6=$ Additive value due to the number of holidays

\section{Data Analysis}

The collected data were analyzed using the Microsoft Excel program. The participants' general characteristics, direct nursing time, and nursing intensity for each date by patient classification groups were analyzed using descriptive statistics such as frequency, percentage, and average. Direct nursing time among the nursing unit nurses, direct nursing time per patient classification point or nursing intensity point, and direct nursing time per patient were calculated using Microsoft Office Excel 2017. 


\section{Results}

1. Calculation of patient classification and nursing intensity based on nursing needs

The average daily number of patients was $39.7,67.7$, and 20.4 while patient classification scores per patient were $64.1,54.7$, and 51.0 points in the internal medicine, surgical, and comprehensive nursing care units, respectively. Using the calculation method presented by Fagerström et al., [9] the average score for each patient classification group was calculated based on the score for Group 1 to calculate a weighted value. Nursing intensity score was calculated by multiplying the weighted value with the number of patients. They were 5.4, 5.7, and 2.4 in the internal medicine, surgical, and comprehensive nursing care unit, respectively (Table 2).

Table 2

Comparison of nursing intensity by nursing units

\begin{tabular}{|c|c|c|c|c|c|c|c|c|}
\hline \multirow[t]{2}{*}{ Nursing unit } & \multirow[t]{2}{*}{$\begin{array}{l}\text { Patient } \\
\text { classification }\end{array}$} & \multirow{2}{*}{$\begin{array}{l}\text { Average } \\
\text { number of } \\
\text { patients per day } \\
\text { a }\end{array}$} & \multirow{2}{*}{$\begin{array}{l}\text { Patient } \\
\text { classification } \\
\text { score } \\
\text { b }\end{array}$} & \multirow{2}{*}{$\begin{array}{l}\text { Patient } \\
\text { classification } \\
\text { score per patient } \\
\text { c=b/a }\end{array}$} & \multirow{2}{*}{$\begin{array}{l}\text { Weighting } \\
\text { coefficient }\end{array}$} & \multirow{2}{*}{$\begin{array}{l}\text { Nursing } \\
\text { intensity } \\
\text { weighting } \\
\text { coefficient } \\
a^{\star} d\end{array}$} & \multirow[t]{2}{*}{$\begin{array}{l}\text { Average } \\
\text { number of } \\
\text { nurses per } \\
\text { day }\end{array}$} & \multirow[t]{2}{*}{$\begin{array}{l}\text { Nursing } \\
\text { intensity } \\
\text { score per } \\
\text { nurse }\end{array}$} \\
\hline & & & & & & & & \\
\hline \multirow{5}{*}{$\begin{array}{l}\text { Unit } 1 \\
\text { Internal } \\
\text { medicine } \\
\text { unit }\end{array}$} & Group 1 & 11.6 & 446.6 & 38.6 & 1.0 & 11.6 & & \\
\hline & Group 2 & 10.9 & 643.0 & 59.2 & 1.5 & 16.35 & & \\
\hline & Group 3 & 15.6 & $1,268.7$ & 81.5 & 2.1 & 32.76 & & \\
\hline & Group 4 & 1.7 & 185.7 & 108.3 & 2.8 & 4.76 & & \\
\hline & Total & 39.7 & $2,544.0$ & 64.1 & 1.7 & 67.49 & 12.4 & 5.4 \\
\hline \multirow{5}{*}{$\begin{array}{l}\text { Unit } 2 \\
\text { Surgical unit }\end{array}$} & Group 1 & 31.0 & $1,129.0$ & 36.4 & 1.0 & 31 & & \\
\hline & Group 2 & 21.9 & $1,265.7$ & 57.9 & 1.6 & 35.04 & & \\
\hline & Group 3 & 11.6 & 955.4 & 82.6 & 2.3 & 26.68 & & \\
\hline & Group 4 & 3.3 & 351.9 & 107.1 & 2.9 & 9.57 & & \\
\hline & Total & 67.7 & $3,702.0$ & 54.7 & 1.5 & 101.55 & 17.9 & 5.7 \\
\hline \multirow{5}{*}{$\begin{array}{l}\text { Unit } 3 \\
\text { Nursing care } \\
\text { unit }\end{array}$} & Group 1 & 11.3 & 439.0 & 38.9 & 1 & 11.3 & & \\
\hline & Group 2 & 6.0 & 341.7 & 57.0 & 1.5 & 9 & & \\
\hline & Group 3 & 3.0 & 246.1 & 82.0 & 2.1 & 6.3 & & \\
\hline & Group 4 & 0.1 & 15.1 & 106.0 & 2.7 & 0.27 & & \\
\hline & Total & 20.4 & $1,042.0$ & 51.0 & 1.3 & 26.52 & 11.0 & 2.4 \\
\hline
\end{tabular}

2. Calculation of nursing time

The proportion of nurses' non-direct nursing time and break time out of total working time was $41.1 \%, 46.9 \%$, and $74.4 \%$ and $4.1 \%, 3.0 \%$, and $5.1 \%$ in the internal medicine, surgical, and comprehensive nursing care units, respectively. The proportion of direct nursing time was calculated to be $54.7 \%, 50.0 \%$, and $20.5 \%$ in the internal medicine, surgical, and comprehensive nursing care units, respectively.

Specifically, the proportion of meal time was $2.5 \%, 2.1 \%$, and $3.3 \%$ and when converted into time required per nurse, it was $15.5,12.7$, and 18.8 minutes for the internal medicine, surgical, and comprehensive nursing care units, respectively. The average handover time per nurse was $30.5,44.4$, and 58.8 minutes in the internal medicine, surgical, and comprehensive nursing care units, respectively (Table 3). 
Table 3

Total working hours, non-direct nursing time, and leisure time

\begin{tabular}{|c|c|c|c|c|c|c|c|c|c|c|}
\hline & & \multicolumn{3}{|c|}{ Internal medicine unit } & \multicolumn{3}{|c|}{ Surgical unit } & \multicolumn{3}{|c|}{ Nursing care unit } \\
\hline & & $\begin{array}{l}\text { Daily } \\
\text { average } \\
\text { (min) }\end{array}$ & $\begin{array}{l}\text { Average } \\
\text { time per } \\
\text { person } \\
\text { (min) }\end{array}$ & $\%$ & $\begin{array}{l}\text { Daily } \\
\text { average } \\
\text { (min) }\end{array}$ & $\begin{array}{l}\text { Average } \\
\text { time per } \\
\text { person } \\
(\min )\end{array}$ & $\%$ & $\begin{array}{l}\text { Daily } \\
\text { average } \\
\text { (min) }\end{array}$ & $\begin{array}{l}\text { Average } \\
\text { time per } \\
\text { person } \\
\text { (min) }\end{array}$ & $\%$ \\
\hline \multicolumn{11}{|c|}{ Number of nurses (person) } \\
\hline \multirow{2}{*}{\multicolumn{2}{|c|}{$\begin{array}{l}\text { Sum of TWT } \\
\text { Total working time of all nurses (min) }\end{array}$}} & $7,593.6$ & 612.4 & 100 & $10,994.6$ & 614.2 & 100 & $6,283.7$ & 571.2 & 100 \\
\hline & & & & & & & & & & \\
\hline \multirow{11}{*}{$\begin{array}{l}\text { Sum of indirect } \\
\text { nursing time } \\
\text { (min) }\end{array}$} & $\begin{array}{l}\text { 1. Planning and coordinating } \\
\text { nursing activities }\end{array}$ & $1,455.7$ & 117.4 & 19.2 & $2,880.0$ & 160.9 & 26.2 & $2,596.4$ & 236.0 & 41.3 \\
\hline & Hand over & 377.9 & 30.5 & 5.0 & 795.0 & 44.4 & 7.2 & 647.1 & 58.8 & 10.3 \\
\hline & Assessment & 694.3 & 56.0 & 9.1 & $1,614.3$ & 90.2 & 14.7 & $1,626.4$ & 147.9 & 25.9 \\
\hline & Delayed work & 383.6 & 30.9 & 5.1 & 470.7 & 26.3 & 4.3 & 322.9 & 29.4 & 5.1 \\
\hline & 2. Indirect nursing time & $1,667.4$ & 134.5 & 22.0 & $2,279.1$ & 127.3 & 20.7 & $2,080.7$ & 189.2 & 33.1 \\
\hline & Recording & 785.3 & 63.3 & 10.3 & $1,148.3$ & 64.2 & 10.4 & $1,240.7$ & 112.8 & 19.7 \\
\hline & Calls from patients & 219.0 & 17.7 & 2.9 & 294.7 & 16.5 & 2.7 & 284.3 & 25.8 & 4.5 \\
\hline & Calls from patients' family & 198.3 & 16.0 & 2.6 & 215.7 & 12.1 & 2.0 & 162.1 & 14.7 & 2.6 \\
\hline & Administrative work & 260.0 & 21.0 & 3.4 & 253.6 & 14.2 & 2.3 & 124.3 & 11.3 & 2.0 \\
\hline & Notifying doctors & 204.9 & 16.5 & 2.7 & 366.9 & 20.5 & 3.3 & 269.3 & 24.5 & 4.3 \\
\hline & Subtotal & $3,123.1$ & 251.9 & 41.1 & $5,159.1$ & 288.2 & 46.9 & $4,677.1$ & 425.2 & 74.4 \\
\hline \multirow{5}{*}{$\begin{array}{l}\text { Sum of leisure time } \\
(\min )\end{array}$} & Meal & 192.1 & 15.5 & 2.5 & 227.3 & 12.7 & 2.1 & 206.4 & 18.8 & 3.3 \\
\hline & Tea & 53.0 & 4.3 & 0.7 & 36.1 & 2.0 & 0.3 & 43.7 & 4.0 & 0.7 \\
\hline & Restroom & 64.9 & 5.2 & 0.9 & 62.0 & 3.5 & 0.6 & 70.9 & 6.4 & 1.1 \\
\hline & Others & 3.6 & 0.3 & 0.0 & 8.6 & 0.5 & 0.1 & 0.0 & 0.0 & 0.0 \\
\hline & Subtotal & 313.6 & 25.3 & 4.1 & 334.0 & 18.7 & 3.0 & 321.0 & 29.2 & 5.1 \\
\hline \multicolumn{2}{|l|}{ NDNT } & $3,436.7$ & 277.2 & 45.3 & $5,493.1$ & 306.9 & 50.0 & 4,998.1 & 454.4 & 79.5 \\
\hline \multicolumn{2}{|l|}{ DNT } & $4,156.9$ & 335.2 & 54.7 & $5,501.4$ & 307.3 & 50.0 & $1,285.6$ & 116.9 & 20.5 \\
\hline \multicolumn{11}{|c|}{ Formula1: $\sum_{\mathrm{i}=1}^{\mathrm{n}} \mathrm{DNT}_{\mathrm{i}}=\sum_{\mathrm{i}=1}^{\mathrm{n}} \mathrm{TWT}_{\mathrm{i}}-\sum_{\mathrm{i}=1}^{\mathrm{n}} \mathrm{NDNT}_{\mathrm{i}}$} \\
\hline \multicolumn{2}{|c|}{ Average number of practicing nurses } & \multicolumn{3}{|l|}{12.4} & \multicolumn{3}{|l|}{17.9} & \multicolumn{3}{|l|}{11.0} \\
\hline
\end{tabular}

4. Direct nursing time per patient by patient classification groups

The direct nursing time per patient calculated through patient classification groups in internal medicine unit was 1.0, 1.5, 2.2, and 2.9 hours for Groups 1, 2, 3 , and 4 , respectively; and in the surgical unit was $0.9,1.4,2.1$, and 2.6 hours for Groups 1, 2, 3, and 4, respectively. Further, in the comprehensive nursing care unit it was $0.8,1.2,1.7$, and 2.2 hours for Groups $1,2,3$, and 4 , respectively (Table 4).

5. Calculation of optimal number of nurses in the internal medicine unit 
Direct nursing time per patient in the nursing units

\begin{tabular}{|c|c|c|c|c|}
\hline \multirow[t]{3}{*}{ Nursing unit } & \multirow[t]{3}{*}{ Patient classification } & \multirow[t]{3}{*}{ WC } & DNT pNI* & DNTpPt \\
\hline & & & \multirow{2}{*}{ Formula2: DNTpNI $=\frac{\sum_{i=1}^{n} \mathrm{DNT}_{\mathrm{i}}}{\sum_{\mathrm{i}=1}^{\mathrm{m}} \mathrm{NIWC}_{\mathrm{i}}}$} & Formula3: DNTpPt $=\mathrm{WC}_{\mathrm{i}} \times \mathrm{DHpNI}$ \\
\hline & & & & \\
\hline \multirow[t]{4}{*}{ Internal medicine unit } & Group 1 & 1.0 & 61.6 & DNTpPt1 $=61.6 \mathrm{mins}(=1.0 \mathrm{hrs})$ \\
\hline & Group 2 & 1.5 & 61.6 & DNTpPt2=92.4 mins $(=1.5 \mathrm{hrs})$ \\
\hline & Group 3 & 2.1 & 61.6 & DNTpPt3=129.3 mins(=2.2 hrs) \\
\hline & Group 4 & 2.8 & 61.6 & DNTpPt4= 172.5 mins $(=2.9$ hrs $)$ \\
\hline \multirow[t]{4}{*}{ Surgical unit } & Group 1 & 1.0 & 54.2 & DNTpPt1 = $54.2 \mathrm{mins}(=0.9 \mathrm{hrs})$ \\
\hline & Group 2 & 1.6 & 54.2 & DNTpPt2=86.7 mins $(=1.4 \mathrm{hrs})$ \\
\hline & Group 3 & 2.3 & 54.2 & DNTpPt3=124.6 mins(=2.1 hrs) \\
\hline & Group 4 & 2.9 & 54.2 & DNTpPt4= $157.1 \mathrm{mins}(=2.6 \mathrm{hrs})$ \\
\hline \multirow[t]{4}{*}{ Nursing care unit } & Group 1 & 1 & 48.5 & DNTpPt1 $=48.5 \operatorname{mins}(=0.8 \mathrm{hrs})$ \\
\hline & Group 2 & 1.5 & 48.5 & DNTpPt2=72.7 mins(=1.2 hrs) \\
\hline & Group 3 & 2.1 & 48.5 & DNTpPt3=101.8 mins(=1.7 hrs) \\
\hline & Group 4 & 2.7 & 48.5 & DNTpPt4= 130.9 mins $(=2.2 \mathrm{hrs})$ \\
\hline \multicolumn{5}{|c|}{ WC: Weighting coefficient, DNTpNI: Direct nursing time per nursing intensity weighting coefficient, DNTpPt: Direct nursing time per patient, } \\
\hline \multicolumn{5}{|c|}{ * Medical: Formula $2: \mathrm{DNTpNI}=\frac{\sum_{\mathrm{i}=1}^{\mathrm{n}} \mathrm{DNT}_{\mathrm{i}}}{\sum_{\mathrm{i}=1}^{\mathrm{m}} \mathrm{NIWC}_{\mathrm{i}}}=\frac{4,156.9 \mathrm{mins}}{67.5 \text { points }}=61.6 \mathrm{mins} /$ point } \\
\hline \multicolumn{5}{|c|}{ * Surgical: Formula2 $:$ DNTpNI $=\frac{\sum_{\mathrm{i}=1}^{\mathrm{n}} \mathrm{DNT}_{\mathrm{i}}}{\sum_{\mathrm{i}=1}^{\mathrm{m}} \mathrm{NIWC}_{\mathrm{i}}}=\frac{5,501.4 \mathrm{mins}}{101.6 \text { points }}=54.2 \mathrm{mins} / \mathrm{point}$} \\
\hline \multicolumn{5}{|c|}{ * Mixed:Formula2 $:$ DNTpNI $=\frac{\sum_{\mathrm{i}=1}^{\mathrm{n}} \mathrm{DNT}_{\mathrm{i}}}{\sum_{\mathrm{i}=1}^{\mathrm{m}} \mathrm{NIWC}_{\mathrm{i}}}=\frac{1,285.6 \mathrm{mins}}{26.5 \text { points }}=48.5 \mathrm{mins} / \mathrm{point}$} \\
\hline
\end{tabular}

The optimal number of nurses in the internal medicine, surgical, and comprehensive nursing care units were calculated by reflecting the nursing time composition and intensity among nurses working in each unit and summing up the calculated nursing time by patient classification groups. The results revealed that the calculated optimal number of nurses was $25(n=24.6), 37(n=36.9)$, and $22(n=21.2)$ in the internal medicine, surgical, and comprehensive nursing care units, respectively. At the time of data collection, 20, 28, and 22 nurses were assigned in these units, respectively. Therefore, if the number of previously assigned nurses was subtracted from the calculated optimal number, 5 and 9 additional nurses would be needed in the internal medicine and surgical units, respectively; however, the number of nurses in the comprehensive nursing care unit was found to be appropriate (Table 5).

Table 5

Calculation of the optimal number of nurses in nursing units

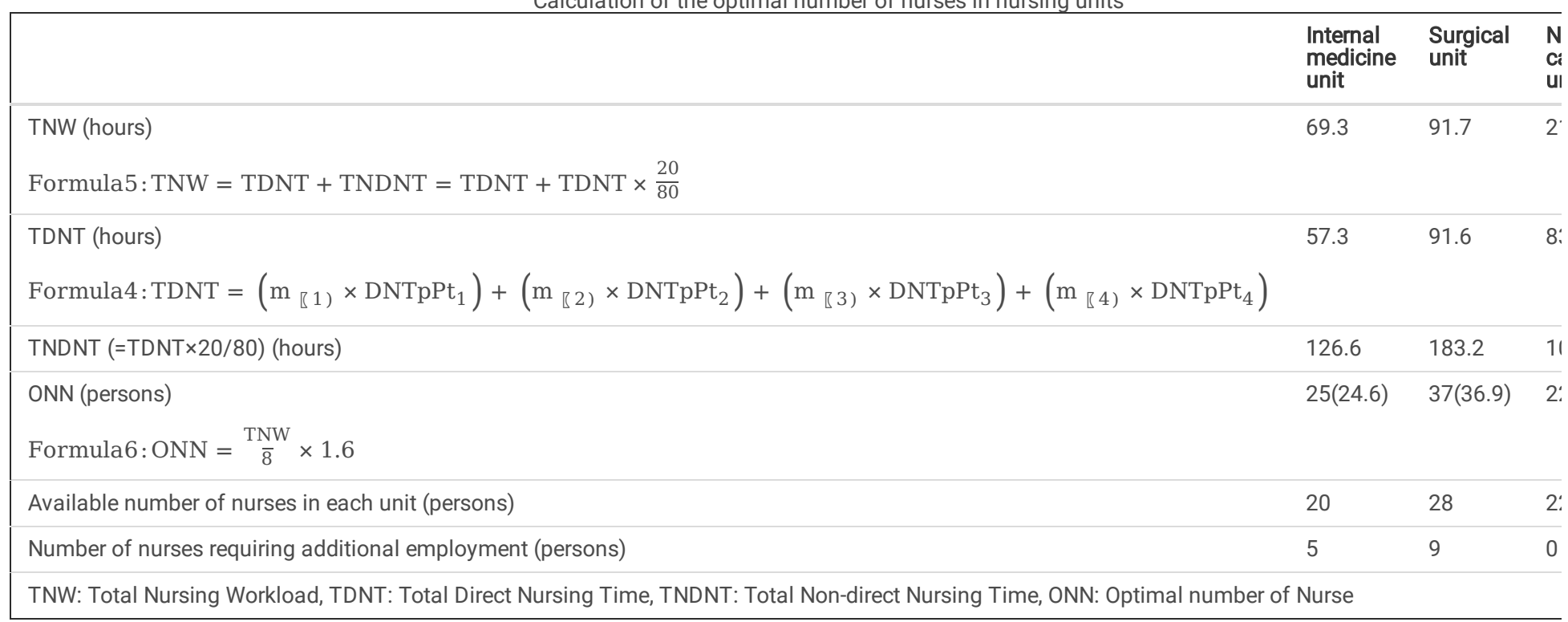




\section{Discussion}

Currently, the most recommended method for calculating the optimal number of nurses in hospital nursing units is to use nursing time by patient classification based on nursing needs. When calculating nursing time in South Korea, observers directly measure all direct nursing activities, which entails a considerable amount of time and effort. Therefore, this study developed a method based on a literature review and expert advice that is different from the existing practice.

This study calculated the optimal number of nurses in each nursing unit using a comprehensive approach based on the total working time, indirect nursing time, and nursing intensity, considering all nurses in each nursing unit. Nurses were asked to respond to questionnaire items related to indirect nursing time immediately after the end of working hours, which could have resulted in recall bias. Whether nursing activities that occur simultaneously with nursing time or only key nursing activities should be reflected in nursing time measurements is a topic of debate and follow-up studies are thus needed.

The results of nursing time composition revealed that the proportions of non-direct nursing time were $45.3 \%, 50.0 \%$, and $79.5 \%$ in the internal medicine, surgical, and comprehensive nursing care units, respectively. According to the data from the Labor Union of Korean Healthcare Service, the average working time per week among hospital nurses in 2016 was 46.6 hours, with $12 \%$ of them working longer than 52 hours per week [20].

In this study, nurses' total working times were calculated to be 7,593.6, 10,994.6, and 6,283.7 minutes with 612.4 (10.2 hours), 614.2 (10.2 hours), and 571.2 minutes ( 9.5 hours) per nurse in the internal medicine, surgical, and comprehensive nursing care units, respectively. The average working time per week is 51 , 51 , and 47.6 hours in the internal medicine, surgical, and comprehensive nursing care units, respectively, indicating a slightly longer duration than reported by the Labor Union of Korean Healthcare Service [20]. Meal time out of the total working time was 192.1 minutes with 15.5 minutes per nurse, 227.3 minutes with 12.7 minutes per nurse, and 206.4 minutes with 18.8 minutes per nurse in the internal medicine, surgical, and comprehensive nursing care units, respectively, indicating that the meal time was the longest in the comprehensive nursing care unit. It could be estimated that the meal time in all three units respectively accounted for $2.5 \%, 2.1 \%$, and $3.3 \%$ of the total working time, indicating that nurses hurriedly eat meals in substantially limited time ( 20 minutes). The Labor Standards Act, Article 54 [21] stipulates that workers should be given a rest break of 30 minutes or longer or 1 hour or longer if they work 4 or 8 hours, respectively. Break times including meal and personal times were very small, comprising $4 \%$ of the total working time, suggesting that there is high working intensity in clinical practice. Therefore, it is essential to secure a minimum meal time, provide break opportunities to enhance nurses' well-being, and create a nursing working environment that encourages nurses to serve effectively for long periods [22].

Nursing intensity includes nurses' technical and physical efforts, mental efforts, and judgment and nursing time. However, this study calculated a representative value of nursing intensity in each nursing unit using weighting coefficients by patient classification groups [9]. The results revealed that the nursing intensity score per patient was $5.4,5.7$, and 2.4 points in the internal medicine, surgical, and comprehensive nursing care units, with nursing intensity in the surgical unit being highest. This nursing intensity index makes it possible to directly compare nursing intensity scores and can be effectively used for nurse staffing at hospitals.

The total nursing intensity score in the nursing units was $67.49,101.55$, and 26.52 points in the internal medicine, surgical, and comprehensive nursing care units, respectively. In a study by Lundgren-Laine and Suominen [23], the average nursing intensity score in the intensive care unit was found to be 12.4 points. In a study by Fagerströmn and Rauhala [24], the average nursing intensity per patient was found to be 13.4 points in 86 nursing units of 14 hospitals in Finland. Compared with the study results by Fagerströmn and Rauhala [24], the nursing intensity in this study was high. Although it is difficult to directly compare the two studies, such a difference in nursing intensity may be attributed to differences in working environments, data collection period, and study participants.

Park et al. [25] estimated nursing costs by patient classification groups in a general nursing unit and revealed that the proportion of direct nursing time was $44.1 \%$ of the average total nursing time per patient per day, while that of non-direct nursing time was $55.9 \%$. This study's results revealed that the proportion of non-direct nursing time in the internal medicine and surgical units was less than $50 \%$, while that of non-direct nursing time was $74.4 \%$, which indicate a distinct difference according to the units' characteristics.

To determine the appropriate nurse staffing in nursing units, factors related to a particular patient's nursing needs should be identified [26]. Fagerström et al. [27] claimed that personal characteristics of inpatients such as gender, age, health status, and situational factors affected their nursing needs, thereby affecting nurses' workload and nursing intensity. It is also important to distinguish between patient- and unit-related workload when measuring nurses' workload by a patient classification system based on the measurement of nursing intensity. It has been pointed out that when measuring nursing intensity, only nurses' workload related to patients was measured, while workload related to the unit to which nurses belonged was not included [28]. In other words, although nurses' workload may increase due to factors related to the respective units, their unit-related workload may be overlooked and may thus be underestimated.

For example, some patients are unstable and require continuous observation and intensive care, therefore, although the severity is high, their dependence may be low because they can complete their activities of daily living by themselves. However, patients in the rehabilitation/recovery phase may be stable, therefore, although their severity is low, their dependence may be high as they cannot complete their daily activities by themselves. Therefore, it is more reasonable to independently evaluate and typify the two areas of severity and dependence rather than evaluating the need for nursing as one dimension [16].

Patients' individual characteristics, such as gender, age, diagnosis, length of hospital stay, activities of daily living, weight, presence or absence of mental illness, terminal patient status, route of admission, surgical status, and the need for a guardian or a privately employed caregiver, were differentially scored and reflected in examining nursing needs using the patient classification tool. The handover time for individual patients was divided into $<30$ minutes and $\geq$ 30 minutes, and was differentially scored. The number of times required for nursing assessment and planning nursing activities was also subdivided and scored. The number of times doctors were notified was divided into $<5$ times, $\geq 5$ times, $<10$ times, and $\geq 10$ times and differentially scored. Related to 
training and supervising new nurses, efforts were made to reflect situational factors related to nurses, such as adjusting scores for preceptors whose preceptee had $<2$ or $\geq 2$ months of experience.

To determine whether the nurse staffing level is appropriate for patient care, an accurate basis for nursing needs [8] with a detailed patient classification tool to calculate the optimal number of nurses is required. However, if additional indicators or scales are added, it will be another burden for nurses to observe patients and record data every day as in the current system, with the accuracy of data being lower than it is now [8].

This study's results revealed that the optimal number of nurses in each nursing unit was 25,37 , and 22 , which amounts to 1.80 , 1.94 , and 1.0 beds per nurse in the internal medicine, surgical, and comprehensive nursing care units, respectively, corresponding to nurse staffing grade 1 level. This proves that applying the nurse staffing grade 1 for general units to the respective nursing units is an appropriate staffing level.

South Korea's nursing workforce problem is not a shortage of licensed nurses, but one of an active nursing workforce, due to working conditions. To create an environment in which experienced nurses can continue to work effectively, it is necessary to reflect an experienced nurse retaining index in the reimbursement policies or to develop policies that offer economic rewards for experienced nurses and build stable working environments.

This study's limitations are as follows: Since it involved only three nursing units at a single hospital, its generalizability may be limited in South Korea. Repetitive studies are needed to verify whether the research method used is applicable even in situations where the size and type of medical institutions, nursing units' characteristics, and the level of securing nursing personnel are different.

Despite these limitations, this study's results are significant: First, previous studies have measured nursing needs to calculate nursing workload. However, this study measured nursing intensity in the nursing units using patient classification scores based on nursing needs, presenting it as coefficients in the nursing units. This can be a useful indicator for the allocation of resources such as workforce at hospitals by comparing nursing intensity between nursing units. Second, this study proposed a new approach to the current situation that lacks various attempts to develop calculation methods for optimal nurse staffing.

\section{Conclusion}

This study attempted to calculate not only the direct nursing time per patient and nursing intensity per nurse in nursing units using data from a survey on total working time and indirect nursing time, but also the direct nursing time by patient classification group and the optimal number of nurses in nursing units to provide basic data for calculating the required number of nursing personnel. The nursing intensity score per nurse in each nursing unit was the highest in the surgical unit, followed by the internal medicine and the comprehensive nursing care units. The results of comparing the optimal number of nurses in each nursing unit, calculated by reflecting nursing time and nursing intensity with the currently assigned number of nurses, revealed that additional nurses were needed in the internal medicine and surgical nursing units. The results also revealed that break time was not properly guaranteed during working hours. Therefore, it is necessary to secure an optimal number of nurses through additional employment and to create a working environment encouraging nurses to work effectively for long periods.

\section{Abbreviations}

KPCSNI: Korean Patient Classification System on Nursing Needs for Intensive Care Units

PAONCIL: Professional Assessment of Optimal Nursing Care Intensity Level

NFDP: Nursing Fee Differentiation Policy

\section{Declarations}

\section{Ethics approval and consent to participate}

This study was conducted after explaining the purpose to the head of the nursing department at the study hospital. The researchers visited the nursing units to explain this study's purpose. Nurses who agreed in writing to participate were selected. The anonymity of all the data they provided was guaranteed, and they were assured that they could withdraw from participation at any time if they so wished. This study was approved by the Institutional Review Board at C University for the development of a nurse staffing prediction model based on nursing intensity in nursing units (approval number: 1040271-201808-HR026). The researchers obtained written informed consent from each participant. The consent form states that participation is voluntary, the anonymity of participants is protected, and participants may withdraw without disadvantage if they do not want to participate. A study on the calculation of the optimal number of nurses based on nursing intensity in the intensive care unit using the same research model has been published in the Korean Journal of Hospital Management [3].

\section{Consent for publication}

Not applicable

\section{Competing interests}

The authors declare that they have no competing interests

Availability of data and materials 
Data sharing is not applicable to this article

\section{Acknowledgement}

We would like to thank Editage (www.editage.co.kr) for English language editing.

\section{Funding}

This paper was also supported by Wonkwang University in 2020. Sponsors did not exert influence in any process of research design, data analysis and interpretation, and submission of manuscripts.

\section{Author contributions}

YK conceived the study, participated in its design and coordination, and drafted the manuscript. BP participated in the design of the study and performed the statistical analysis. Both authors read and approved the final manuscript.

\section{References}

1. Nantsupawat A, Nantsupawat R, Kulnaviktikul W, McHugh MD. Relationship between nurse staffing levels and nurse outcomes in community hospitals, Thailand. Nurs Health Sci. 2015;17(1):112-8. doi:10.1111/nhs.12140.

2. Kim IS, Jang KS, Lee MH, Ha NS, Lee TW, Lim JS, et al. Edition latest nursing management. 4th ed. Seoul: Hyunmoonsa; 2015

3. Ko Y, Park BH. Calculation of optimal number of nurses based on nursing intensity of intensive care units. KJ-HSM. 2020;25(3):14-29.

4. Kim, J. K. (2007). Job satisfaction and patient satisfaction related to nurse staffing. J Korean Nurs Adm Acad Soc. 13(1):98-108.

5. Health Insurance Review \& Assessment Service. (2017). Inpatient Fee in South Korea. Retrieved from http://www.hira.or.kr/dummy.do? pgmid=HIRAA020033000000\#none.

6. Shin S, Park JH, Bae SH. Nurse staffing and nurse outcomes: a systematic review and meta-analysis. Nurs Outlook. 2018; 66:273-82.

7. Kim E, Kim H, Kim M. Development of patient classification system based on nursing intensity in stroke unit. J Korean Acad Nurs Adm. 2014;20(5):54557.

8. Kim JH, Kim SJ, Park JH, Park ET, Jeong SY, Lee EH. Adequacy of nurse staffing level in integrated nursing care. J Korean Acad Nurs Adm. 2018;24(4):288-307.

9. Fagerström L, Rainio AK, Rauhala A, Nojonen K. Professional assessment of optimal nursing care intensity level: a new method for resource allocation as an alternative to classical time studies. Scandinavian J Caring Sci. 2000;14(2):97-104.

10. Santos TA, Santos HS, Sampaio ES, Melo CMM, Souza EA, Silva Pires CG. Intensity of nursing work in public hospitals. Rev Lat Am Enfermagem. 2020;28:e3267. doi:10.1590/1518-8345.3221.3267.

11. National Institute for Health and Care Excellence. Safe Staffing for nursing in adult in patient wards in acute hospitals: safe staffing guideline 1. London: National Institute for Health and Care Excellence (NICE), 2014.

12. Driscoll A, Grant MJ, Carroll D, Dalton S, Deaton C, Jones I, Lehwaldt D, McKee G, Munyombwe T, Astin F. The effect of nurse-to-patient ratios on nursesensitive patient outcomes in acute specialist units: a systematic review and meta-analysis. Eur J Cardiovasc Nurs. 2018;17(1):6-22

13. Ko Y, Park B, Lee H, Kim D. Developing and testing a Korean patient classification system for general wards based on nursing intensity. Nursing Open 2021;8(4):1870-8.

14. Kim JH, Kim SJ, Park ET, Jeong SY, Lee EH. Policy issues and new direction for comprehensive nursing service in the national health insurance. J Korean Acad Nurs Adm. 2017;23(3):312-22. doi:0.11111/jkana.2017.23.3.312

15. Park SA. Nursing management. 1st ed. Seoul: Parkmungak; 2005

16. Hoi SY, Ismail N, Ong LC, Kang J. Determining nurse staffing needs: the workload intensity measurement system. J Nurs Manag. 2010;18(1):44-53.

17. Park YS, Song R. Estimation of nurse staffing based on nursing workload with reference to a patient classification system for a intensive care unit. $J$ of Korean Critical Care Nurs. 2017;10(1):1-12

18. Cho SH, Lee JY, June KJ, Hong KJ, Kim YM. Nurse staffing levels and proportion of hospitals and clinics meeting the legal standard for nurse staffing for 1996 2013. J Korean Acad Nurs Adm. 2016;22(3):209-19.

19. Lee SY, Jung HS, Sin SJ, Chang JK, Kim JH, Yoon KJ, et al. A study on the analysis and improvement of nursing work conditions. Korea Institute for Health and Social Affairs Report. Seoul: Korea Institute for Health and Social Affairs. 2018. Report No.: HETA 12-1050400-000033-01.

20. Statistics Korea. Labor union of Korean Health care service. 2019. Seoul: Current status of work condition of healthcare workforce. Accessed 6 Mar 2020.

21. Korea Ministry of Government Legislation. Labor Standards Act. Seoul: Korea Ministry of Government Legislation; 2019. http://www.la-wgokr/lsSc.do? tabMenuld=tab18\&query=\%EA\%B7\%BC\%EB\%A1\%9C\%EA\%B8\%B0\%EC\%A4\%80\%EB\%B2\%95\%2054\%EC\%A1\%B0\#J54:0 Accessed 6 Mar 2020.

22. Hwang SW, Bae SH. Current status of nurse working hours, related issues and improvements. Health Nurs. 2017;29(2):1-9.

23. Lundgrén-Laine H, Suominen T. Nursing intensity and patient classification at an adult intensive care unit. Intensive Crit Care Nurs. 2007;23(2):97-103.

24. Fagerström L, Rauhala A. Finn intensity benchmarking in nursing. Proceedings of the Association of Finnish Local and Regional Authorities; $2000-2002$. Helsinki, Finland: Suomen Kuntaliitto; 2003. 
25. Park JH, Song MS, Sung YH, Sim WH. Estimation of nursing costs by patient classification system (PCS) in general nursing units. J Korean Acad Nurs Adm. 2003;9(3):379-89.

26. Padilha KG, Caedoso de Sousa RM, Queijo AF, Mendes AM, Miranda DR. Nursing activities score in the intensive care unit: analysis of the related factors. Intensive Crit Care Nurs. 2008;24(3):197-204.

27. Fagerström L, Lønning K, Andersen MH. The RAFAELA system: a workforce planning tool for nurse staffing and human resource management. Nurs Manag (Harrow). 2014;21(2):30-6. Morris R, MacNeela P, Scott A, Treacy P, Hyde A. Reconsidering the conceptualization of nursing workload: literature review. J Adv Nurs. 2007;57(5):463-71. 